TI 2015-017/V

Tinbergen Institute Discussion Paper

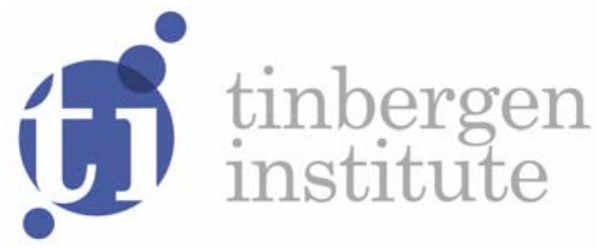

\title{
Labor Market Equilibrium with Public Employment Agency
}

\author{
Christian Holznerl
}

Makoto Watanabe 2

1 University of Munich, Germany;

2 Faculty of Economics and Business Administration, VU University Amsterdam, and Tinbergen Institute, the Netherlands. 
Tinbergen Institute is the graduate school and research institute in economics of Erasmus University Rotterdam, the University of Amsterdam and VU University Amsterdam.

More TI discussion papers can be downloaded at http://www.tinbergen.nl

Tinbergen Institute has two locations:

Tinbergen Institute Amsterdam

Gustav Mahlerplein 117

1082 MS Amsterdam

The Netherlands

Tel.: +31(0)205251600

Tinbergen Institute Rotterdam

Burg. Oudlaan 50

3062 PA Rotterdam

The Netherlands

Tel.: +31(0)10 4088900

Fax: $+31(0) 104089031$

Duisenberg school of finance is a collaboration of the Dutch financial sector and universities, with the ambition to support innovative research and offer top quality academic education in core areas of finance.

DSF research papers can be downloaded at: http://www.dsf.nl/

Duisenberg school of finance

Gustav Mahlerplein 117

1082 MS Amsterdam

The Netherlands

Tel.: +31(0)20 5258579 


\title{
Labor Market Equilibrium with Public Employment Agency*
}

\author{
Christian Holzner ${ }^{\dagger}$ \\ Makoto Watanabe $\ddagger$
}

February 3, 2015

\begin{abstract}
We develop and empirically test a labor market model with Public Employment Agencies (PEA) in order to understand why not all vacancies use the costless services provided by the PEA. We show that both the search market and the PEA can be active in equilibrium. In such an equilibrium, workers with a higher productivity have a higher chance of receiving a job offer and hence a higher value of searching privately. This enables firms in the search market to attract a better pool of applicants by posting a higher wage than firms registered with the PEA. Registered firms have no incentive to compete with firms in the search market since the application process in the PEA is coordinated so that the offered wage cannot affect the meeting probability. Using the German Job Vacancy Survey, we test the implications of our theory and find strong support for it.
\end{abstract}

Keywords: Labor Search, Intermediation, Public Employment Agency

JEL: J6

\footnotetext{
*We are grateful to Andrey Launov for his suggestions regarding the empirical part, and Christopher Flinn and Boyan Javanovic for their comments and suggestions.

${ }^{\dagger}$ Ifo Institute for Economic Research at the University of Munich. Address: Poschingerstrasse 5, 81679 Munich, Germany. Email: holzner@ifo.de. Tel.: +49-899224-1278, Fax: +49-899224-1604.

$\ddagger^{\ddagger}$ Department of Economics, FEWEB, VU University Amsterdam, Tinbergen Institute. Address: Department of Economics, VU Amsterdam, De Boelelaan 1105, NL-1081 HV Amsterdam, The Netherlands. Email: makoto.wtnb@gmail.com. Tel.: +31-20598-6030. Fax: +31-20598-9870.
} 


\section{Introduction}

In most industrialized countries Public Employment Agencies (hereafter, PEA) provide job-brokering services - arrange job seekers to obtain jobs and employers to fill vacancies. The market places provided by PEAs comprise all unemployed, who register to receive benefits, and are open to all job seekers and vacancies at zero cost. Still, the costless services provided by the PEAs do not attract all of them. This is even more puzzling than it sounds given the fact that the advances in technology make it possible for the PEAs to centralize the job applications and to mitigate coordination frictions present in decentralized search markets.

According to the existing empirical literature unemployment benefit recipients, low skilled workers, long-term unemployed and workers with few job opportunities are more likely to use a PEA. ${ }^{1}$ While these findings are indicative of the job seekers' self-selection into (or not into) the PEA, they are less informative of how labor markets with the PEA work and why firms use different search channels.

In order to gain the entire picture of labor market equilibrium in the presence of the PEA, we develop a simple theory and empirically test its predictions. In particular, we aim at understanding why the costless and coordinated job-brokering service offered by the PEA cannot attract all the available vacancies in the first place. ${ }^{2}$ Our theoretical model extends the pioneering work on the role of PEAs by Pissarides (1979). Like him we assume that all unemployed are registered at the PEA, that searching in the decentralized market is costly for workers, and that firms can choose between two alternative methods of finding a worker: the search market and the PEA. There are two major differences between his and our model. First, workers are homogeneous in Pissarides (1979), while the key ingredient of our model is that workers differ in productivity, and that firms have some technologies to screen applicants, imperfectly though, at the recruitment stage. Second, Pissarides (1979) assumes an exogenous and identical wage in both markets. In contrast, by adopting a directed search approach, we show that firms in the decentralized market choose to post higher wages than firms registered with the PEA in order to attract workers despite their search cost. Since the value of searching in the private market is higher for high productivity workers, the endogenous wage differential allows firms in the private market to attract a better pool of applicants. In an extension, Pissarides (1979) considers the limiting case where search frictions are eliminated in the PEA and finds that in this case the private market collapses and all workers search via the PEA. This is in contrast to our model. We show that the positive selection of workers in the search market ensures the existence of the decentralized search market even if the PEA manages to match the short side of the market.

\footnotetext{
${ }^{1}$ See Holzer (1988) and Blau and Robins (1990) for the US, Osberg (1993) for Canada and Gregg and Wadsworth (1996) for the UK.

${ }^{2}$ Pollard et al. (2012) report that in the Unitied Kingdom only 39 percent of all establishments used the Jobcentre Plus in 2011 and Müller et al. (2011) report that in Germany the corresponding number is 48 percent in 2010.
} 
We use the German Job Vacancy Survey, a representative establishment data-set collected by the Federal Employment Agency in Germany, which contains numerous questions regarding the recruitment process, to investigate the explanation suggested by our theory. We find that the fraction of suitable applicants at vacancies registered with the PEA is about 10 percent lower than at vacancies that only use decentralized search channels. This evidence is complementary to the evidence provided in the existing literature, which shows that less suited workers are more likely to use PEAs (see footnote 1). Our complement is important in order to understand the role of PEAs in the labor market, since the evidence from the workers' side alone does not necessarily imply that the mechanism proposed by our theory is at work in reality. It could for example be that in contrast to our theory PEAs can detect low type workers, sort them out, and help registered firms overcome information asymmetries. Instead, our empirical result that registered firms are less likely to get better applicants therefore clarifies that PEAs are not able to screen applicants as good as the search market.

Given that registered firms receive a less suited pool of applicants, the question arises why firms register at all at PEAs. Our theory suggests that under the job-brokering service provided by PEAs, the job application process is coordinated so that firms do not need to compete through wage offers to attract workers' applications. This allocation mechanism allows registered firms to fill their vacancies with lower wage costs, since there is always a chance that even high productivity workers do not receive any offers elsewhere. The empirical evidence that workers that found their job through the PEA receive lower wage offers than workers that found their job through other search channels is mixed. Holzer (1988) reports for the US and Addison and Protugal (2002) for Portugal that workers, who searched through the PEA, received lower wage offers (after controlling for worker characteristics). Osberg (1993) finds for Canada and Weber and Mahringer (2002) for Austria that the wage difference disappears after controlling for worker characteristics. Our evidence shows that firms registered at the PEA are more likely to report difficulties in the recruitment process, because their applicants demanded higher wages. This supports not only the hypothesis that firms, which register their vacancy with the PEA, offer lower wages than firms, which did not register their vacancy. It also implies that one and the same worker can receive multiple wage offers, which differ systematically depending on whether the vacancy is registered with the PEA or not. This is in line with our theory, which suggests that the job-brokering activity and its coordinated job application are responsible for lower wages offers at PEAs.

Our paper is also related to the literature of intermediation. Watanabe $(2010,2013)$ provide a directed search model of middlemen (e.g., retailers, wholesalers, trading entrepreneurs, dealers or brokers of services and durable goods and assets). ${ }^{3}$ He demonstrates that backed by the capability of dealing

\footnotetext{
${ }^{3} \mathrm{~A}$ seminal work in the literature of middlemen is Rubinstein and Wolinsky (1987). While most of the models in the literature would be viewed as describing general markets, there are some models (e.g., Yavas, 1994, Masters, 2007, Watanabe, 2010) that feature labor market intermediation or turnover behaviors. See Watanabe (2013) for the references of the recent contributions.
} 
with many agents at a time, middlemen find it optimal to provide customers with proximity or a lower likelihood of experiencing stockout, charging a higher price. That the PEA in the present framework provides a coordinated transaction is similar to his middlemen's capability of pursuing large-scaled dealings. However, in contrast to the literature, the PEA does not act as a private agent, who charges a premium for their service, which raises the question why not all agents use the middlemen. In a recent progress, Gautier, Hu and Watanabe (2015) offer a hybrid model of middlemen and marketmakers (i.e., platform), and study the choice of the two alternative intermediation modes. Unlike in the present model, agents are homogeneous and the issue of differential composition of heterogeneous agents is not addressed.

In the directed search literature, Albrecht, Gautier and Vroman (2006) develop a model where workers simultaneously apply for multiple jobs and show that in equilibrium firms engage in Bertrand competition, if their applicant receives two or more offers. Unlike in their setup, we assume wage commitment and show that a low wage can survive in equilibrium due to the coordinated allocation mechanism used by the PEA. Galenianos and Kircher (2009) consider the case of commitment with homogeneous workers and show the existence of an equilibrium wage dispersion. In our model, workers can apply only to one firm in the decentralized market, just like in the standard directed search models, but there are some workers who use both the search market and the PEA, and hence receive multiple offers, one from the search market and the other from the PEA. In this setup we show that, while the search market has a unique wage, a wage differential exists between the search market and the PEA. Our modeling choice reflects the institutional difference between the two market places in reality, ultimately to understand how labor markets work in the presence of the PEA.

There are very few other papers that consider the role of PEAs. Fugère et al. (2009) uses a structural partial search equilibrium model to investigate the hypothesis by Pissarides (1979) that more efficient PEAs crowed out private search effort. Their partial equilibrium model considers exogenous search channel specific wage offer distributions and allows for endogenous search intensity of workers. Using French data to structurally estimate the model they find that the exit rate from unemployment increases with the arrival rate of job contacts obtained by the PEA. This is especially the case for low-skilled workers. Launov and Wälde (2014) use a structural model to analyze to which extend an increase in operating efficiency of PEAs on the one hand and a reduction of unemployment benefits on the other are responsible for the decline in unemployment in Germany from $11.7 \%$ in 2005 to $7.8 \%$ in 2008 .

Finally, Casella and Hanaki (2008) and Galenianos (2013) study firms' use of referrals by their own employees in addition to formal market channels. ${ }^{4}$ Referred workers may be more suited for the job because referred workers can carry a more accurate productivity signal than workers contacted through

\footnotetext{
${ }^{4}$ Galenianos (2014) models the use of referrals by expanding firms in order to explain inter-industry variation in aggregate matching efficiency.
} 
a formal search channel. The search channels in our model do not differ in their signaling ability. They differ in the allocation mechanism used. In the search market firms can increase the probability to meet a worker by offering a higher wage, while firms' meeting probability at the PEA is independent of the wages they offer. The novelty of our paper is to show that the higher degree of wage competition among firms in the search market compared to the PEA leads to a positive selection of applicants.

The sequel of the paper is organized as follows. Section 2 presents the theoretical model of the labor market in the presence of the PEA. In Section 3, we use data from the German Job Vacancy Survey to test the predictions of our theory. Section 4 concludes. All proofs are collected in the Appendix.

\section{Theoretical part}

\subsection{The model}

We consider an economy with unit mass of unemployed workers and mass $v \in(0, \infty)$ of firms. Each firm has one job vacancy that needs to be filled, and each worker wishes to find a job. There are two types of workers. A fraction $m$ of them are productive workers, who can produce an output normalized to 1 , and the rest are unproductive workers, who produce 0 . The worker's type is private knowledge. Firms possess screening technologies to hire workers. But their technologies are not perfect. We assume that firms can screen only one worker and that screening can fail with probability $\delta \in(0,1)$. So firms can detect an unproductive worker only with probability $1-\delta$.

There are two channels through which matching between firms and unemployed workers can occur. One is a public employment agency (hereafter, PEA), where all unemployed workers are registered in order to collect unemployment benefit (normalized to zero). We model the job-brokering service provided by the PEA as follows. All job applications by registered workers are coordinated so that workers and firms are brought together on a one by one basis. Denote by $a \in(0,1]$ the maximum number of matching pairs the PEA can propose. $a$ is a technological parameter and represents the efficiency of the PEA. The other channel is a search market, which may be referred to as a decentralized market or a private market. Here, unlike in the PEA, search is costly for workers and job applications are not coordinated. Workers have to incur an individual specific search cost represented by $c$ drawn from a uniform distribution with support $[0,1]$. The parameter $c$ is uncorrelated with the worker's type. The firms' cost required to post a vacancy is normalized to zero for both markets. How workers search without coordination will be specified below.

The economy lasts only one period and has the following stages. In the first stage, firms decide whether to post their vacancy in the search market or the PEA. Once firms are registered, the PEA selects randomly $\min \{v \rho, a\}$ workers and suggests each of them to match with one of the registered 
firms. In the second stage, all firms post simultaneously a wage at which they are willing to hire a worker. The wage posted in the search market is denoted by $w$, and the wage posted in the PEA by $w_{a}$. Having observed those wages, workers decide whether or not to enter the search market in the third stage. Once in the search market, workers must choose to which firm to send an application. Assuming that each worker can send only one application and that workers cannot coordinate their actions over which firm to apply, we investigate a symmetric equilibrium where all workers use the identical application strategy for any configuration of the announced wages. This is the standard notion of directed search equilibria, see e.g., Peters (1991, 2001), Moen (1997), Acemoglu and Shimer (1999), Shi (2001), Burdett, Shi and Wright (2001) and Guerrieri, Shimer and Wright (2010). Finally, given those applications in the search market or an assigned worker in the PEA, firms select and screen one of their applicants and make a job offer in the final stage. Those workers, who receive multiple offers, can select the highest wage. Once employed, productive workers produce and matched workers and firms receive their payoffs. Unmatched workers and firms get zero payoff.

Pissarides (1979) models search frictions by an exogenous matching function, whereas we assume coordination frictions in the decentralized market and adopt the standard directed search approach. Apart from the theoretical advance of deriving the matching function endogenously, this approach enables us to clarify that the absence of coordination frictions is essential for the PEA to centralize workers applications and job offerings.

\subsection{Equilibrium definition}

In what follows, we construct a search market equilibrium which has the following characteristics. A fraction $\rho \in[0,1)$ of firms registered with the PEA post a wage $w_{a}=0$ and a fraction $1-\rho$ of firms in the search market post a wage $w \in(0,1)$. All the workers are registered in the PEA and accept the wage $w_{a}=0$ if it is the only offer they have received. A productive (an unproductive) worker enters a search market if and only if his search cost is no greater than a reservation value $c^{m}$ $\left(c^{u}\right)$. Given the search behaviors of workers, each individual firm in the directed search market is characterized by a queue of workers, denoted by $x$. The number of applicants each individual firm receives denoted by $n=1,2,3, \ldots$. is a random variable and follows from a Poisson distribution with density $\operatorname{Prob}[n=\tilde{n}]=\left(x^{\tilde{n}} e^{-x}\right) /(\tilde{n} !)$. The expected queue of workers $x$ satisfies

$$
x=\frac{m c^{m}+(1-m) c^{u}}{v(1-\rho)},
$$

where the numerator equals the total number of workers in the search market, $m c^{m}$ productive and $(1-m) c^{u}$ unproductive workers, while the denominator equals the total number of vacancies in the search market. Each productive worker is expected to be hired with probability $\eta(x)=\left(1-e^{-x}\right) / x$ in 
the search market and with probability $\min \{v \rho, a\}$ in the PEA, whereas each unproductive worker is expected to be hired with probability $\delta \eta(x)$ in the search market and with probability $\delta \min \{v \rho, a\}$ in the PEA. Each individual firm employs a productive worker (and can produce output 1) with probability $x \eta(x) m /(m+(1-m) \delta)$ in the search market and with probability $\min \{1, a /(v \rho)\} m\left(1-c^{m} \eta(x)\right)$ in the PEA. In the following we show that workers and firms have no incentive to deviate from the proposed search market equilibrium.

An equilibrium without active search market, i.e., $\rho=1$, will be explained when we describe the first-stage entry decision.

\subsection{Existence and characterization}

Workers' search decision: Assuming for the moment the existence of an equilibrium, we first describe workers' search decision. In any equilibrium where $U^{m}\left(U^{u}\right)$ is the expected value of search for a productive (an unproductive) worker, the participation decision is described by a reservation value of search cost given by

$$
\begin{aligned}
& c^{m}=U^{m}, \\
& c^{u}=U^{u},
\end{aligned}
$$

respectively. Since a productive (an unproductive) worker with search cost $c$ searches if and only if $c \leq c^{m}\left(c \leq c^{u}\right)$, the threshold values $c^{m}$ and $c^{u}$ determine the fraction of productive and unproductive workers that choose to search in the decentralized market.

Given the participation decision, we now describe workers' application decision in the search market. For that purpose, consider a situation in which a firm in the search market deviates to a wage $w^{\prime}>0$, given that all other firms post $w$ with associated queue length $x$. Note that this deviation is a measure zero event for the entire market. Let $x^{\prime}$ be the expected queue of workers at this firm. Then, we must have

$$
U^{m}=\eta\left(x^{\prime}\right) w^{\prime}
$$

where $\eta\left(x^{\prime}\right)=\sum_{i=0}^{\infty} \frac{x^{\prime i} e^{-x^{\prime}}}{i !} \frac{1}{i+1}=\left(1-e^{-x^{\prime}}\right) / x^{\prime}$ is the probability that a productive worker is employed if he applies to this firm. To derive this probability note that if there are $i=0,1,2, \ldots$ other applications to this firm, which happens with probability $\left(x^{\prime i} e^{-x^{\prime}}\right) /(i !)$, then a given worker's application is selected with probability $1 /(i+1)$. Similarly, for unproductive workers, it is

$$
U^{u}=\delta \eta\left(x^{\prime}\right) w^{\prime}
$$

where, the employment probability for an unmotivated worker is given by $\delta \eta\left(x^{\prime}\right)$, since the firm's screening succeeds and detects an unproductive worker only with probability $1-\delta$. Observe that 
$\delta U^{m}=U^{u}$ and so $\delta c^{m}=c^{u}$. Equation (2) defines an implicit equation that determines $x^{\prime}=x\left(w^{\prime} \mid U^{m}\right)$ as a strictly increasing function of $w^{\prime}$ given the market value $U^{m}$.

Firms' wage offers: Given the search behaviors of workers described above, the next step is to characterize the equilibrium wages. Given $w_{a}=0$ in the PEA, we first derive an equilibrium wage in the search market. In any equilibrium where $U^{m}\left(U^{u}\right)$ is the value of a(n) (un)productive worker, the optimal wage of a firm, denoted by $w\left(U^{m}\right)$, satisfies

$$
w\left(U^{m}\right)=\arg \max _{w^{\prime}} x\left(w^{\prime} \mid U^{m}\right) \eta\left(x\left(w^{\prime} \mid U^{m}\right)\right) \frac{m\left(1-w^{\prime}\right)-(1-m) \delta^{2} w^{\prime}}{m+(1-m) \delta} .
$$

Here, the firm with a wage $w^{\prime}$ and a queue $x^{\prime}$ expects to receive at least one application with probability $1-$ Prob. $(n=0)=1-e^{-x^{\prime}}=x\left(w^{\prime} \mid U^{m}\right) \eta\left(x\left(w^{\prime} \mid U^{m}\right)\right)$. Note that there are $m c^{m}$ productive and $(1-m) c^{u}=(1-m) \delta c^{m}$ unproductive workers in the search market, thus in total $[m+(1-m) \delta] c^{m}$ workers. Hence, a randomly selected applicant is a productive worker with probability $m /(m+(1-m) \delta)$, in which case the firm's payoff is $1-w^{\prime}$, and is an unproductive worker with probability $((1-m) \delta) /(m+(1-m) \delta)$. In the latter case, if the firm detects successfully the worker's type, which is possible with probability $1-\delta$, he does not hire this worker, yielding zero payoff. If the screening fails, which occurs with probability $\delta$, then the firm employs this worker, who produces nothing, and the firm's payoff is $-w^{\prime}$.

Substituting out $w^{\prime}$ using equation (2), the objective function of a firm, denoted by $\Pi_{s}\left(x^{\prime}\right)$, can be written as,

$$
\Pi_{s}\left(x^{\prime}\right)=\frac{m\left(x^{\prime} \eta\left(x^{\prime}\right)-x^{\prime} U^{m}\right)-(1-m) \delta^{2} x^{\prime} U^{m}}{m+(1-m) \delta},
$$

where $x^{\prime}=x\left(w^{\prime} \mid U^{m}\right)$ satisfies equation (2). The first-order condition is

$$
\frac{\partial \Pi_{s}\left(x^{\prime}\right)}{\partial x^{\prime}}=\frac{m\left(e^{-x^{\prime}}-U^{m}\right)-(1-m) \delta^{2} U^{m}}{m+(1-m) \delta}=0 .
$$

The second order condition can be easily verified. Rearranging this condition using equation (2) one can obtain

$$
w\left(U^{m}\right)=\frac{m}{m+(1-m) \delta^{2}} \frac{x^{\prime} e^{-x^{\prime}}}{1-e^{-x^{\prime}}} .
$$

In a directed search equilibrium, workers must be indifferent between any of the individual firms, leading to,

$$
\begin{aligned}
w & =\frac{m}{m+(1-m) \delta^{2}} \frac{x e^{-x}}{1-e^{-x}}, \\
U^{m} & =\frac{m}{m+(1-m) \delta^{2}} e^{-x} .
\end{aligned}
$$

Hence, we have shown that given that $w_{a}=0$, the equilibrium wage in the search market $w>0$ is given by equation (3). 
Given $w>0$ in the search market, we show next that the equilibrium wage in the PEA is given by the reservation wage $w_{a}=0$. Given that a proportion $\rho \in[0,1)$ of firms are in the PEA, the wage $w_{a}=0$ in the PEA yields an equilibrium profit,

$$
\Pi_{a}(x)=\min \left\{\frac{a}{v \rho}, 1\right\} m\left(1-c^{m} \eta(x)\right),
$$

where, given the probability of being allocated a worker $\min \{a /(v \rho), 1\}, m\left(1-c^{m} \eta(x)\right)$ represents the number of productive workers, who do not receive a job offer in search market and are wiling to accept $w_{a}=0$.

The PEA matches registered workers and firms using its job-brokering mechanism. This allocation is independent of the wages offered by registered firms. The fact that registered firms cannot increase the PEA-internal matching probability $\min \{a /(v \rho), 1\}$ by offering a higher wage implies that registered firms will never compete among themselves. They will only compete with firms in the decentralized market. This is the reason why a wage offer $w_{a}^{\prime} \in(0, w)$ cannot be profitable since such a deviation implies a mere increase in the wage cost without improving the probability of hiring a productive worker. If a deviating firm posts $w_{a}^{\prime} \geq w$, then it can hire an assigned productive worker, irrespective of whether the worker gets another offer in search market. Hence, the best deviation $w_{a}^{\prime}=w$ yields the profit,

$$
\Pi_{a}^{\prime}=\min \left\{\frac{a}{v \rho}, 1\right\}[m(1-w)-(1-m) \delta w] .
$$

We show in the Appendix that $\Pi_{a}(x)>\Pi_{a}^{\prime}$ for any $x \in(0, \infty)$. Thus, the deviation $w_{a}^{\prime}=w$ is not profitable, because the increase in the probability to hire a productive worker, if the firm offers $w_{a}^{\prime}=w$, is not large enough to compensate for the higher wage cost. It follows that registered firms offer only the reservation wage $w_{a}=0$, because of the absence of PEA-internal competition due to the job-brokering mechanism at the PEA. Thus, $w_{a}=0$ is the unique equilibrium wage in the PEA.

Firms' market choice: In the first stage, firms decide whether to enter the PEA or the search market for hiring a worker. Firms will choose the market that offers the highest expected profit, thereby the equilibrium condition is given by,

$$
\rho=\left\{\begin{array}{cl}
0 & \text { if } \Pi_{a}(x)<\Pi_{s}(x), \\
(0,1) & \text { if } \Pi_{a}(x)=\Pi_{s}(x), \\
1 & \text { if } \quad \Pi_{a}>\Pi_{s},
\end{array}\right.
$$

where the equilibrium queue in the search market $x=x(\rho)$ is given by (1) for $\rho \in[0,1)$. Given this queue, the equilibrium wages $w>0$ in (3) and $w_{a}=0$, and the equilibrium search values of workers $U^{m} \geq 0$ in (4) and $U^{u}=\delta U^{m}$, the equilibrium profit in the PEA, $\Pi_{a}(x)$, is given by (5) and the 
equilibrium profit in the search market is given by

$$
\Pi_{s}(x)=\frac{m}{m+(1-m) \delta}\left(1-e^{-x}-x e^{-x}\right) .
$$

If $\rho=1$, all firms are in the PEA and make the profits $\Pi_{a}=\min \left\{\frac{a}{v}, 1\right\} m$ with the equilibrium wage $w_{a}=0$. Note that since no jobs are posted, the search market only has workers, both productive and unproductive, whose search costs are zero in this equilibrium. If a firm deviates to enter the search market with a wage $w^{\prime}=\epsilon>0$, then the firm meets with a worker for sure, and makes profits, $\Pi_{s}=m(1-\epsilon)$. The proportion of productive workers in the search market is given by $m$, since the density of productive workers and of unproductive workers with zero search costs are the same. This deviation is profitable if and only if $\Pi_{s}>\Pi_{a}$, or $a / v<1$ for an arbitrary small $\epsilon$. Hence, an equilibrium without active search market, i.e., with $\rho=1$, can exist if and only if $a / v \geq 1$, i.e., if the PEA is efficient enough.

Let us first define

$$
v^{*} \equiv \frac{m+(1-m) \delta}{m+(1-m) \delta^{2}} \frac{m}{x^{*}} e^{-x^{*}},
$$

where $x^{*}$ is a unique solution to $\Pi_{a}\left(x^{*}\right)=\Pi_{s}\left(x^{*}\right)$. We now summarize the main result of our analysis on labor market equilibria with the PEA.

Theorem 1 A search market equilibrium with an active PEA, $\rho \in(0,1)$, exists, if and only if $v>v^{*}$, and a search market equilibrium with an inactive PEA, $\rho=0$, exists if and only if $v \leq v^{*}$. This equilibrium is unique if and only if $v>a$. If $v \leq a$ a pure PEA equilibrium, $\rho=1$, also exists.

Our theory estabishes that firms find it optimal to post higher wages in a decentralized search market in order to obtain a better selection of workers. Thus, firms induce workers to search in a costly decentralized market in order to reduce the information friction that is associated with a coordinated market like the PEA. The tradeoff between the search market and the PEA can be seen by looking at the benefits and costs of both markets. The benefit of using the search market is that it attracts a better selection of workers, i.e., the share of productive workers among all applicants is higher in the decentralized search market than in the PEA, i.e., for $\rho \in[0,1)$,

$$
\frac{m}{m+(1-m) \delta}>m \text {. }
$$

The benefit of having a better pool of applicants has to be weighted against the higher wage cost $w>w_{a}=0$, which firms have to pay to workers in order to induce them to engage in costly search in the decentralized market. The wage cost in the decentralized market is lower, when the number of 
firms $v$ is lower so that the search market is less tight and less competitive. Hence, Theorem 1 shows that the search market is used exclusively, $\rho=0$, when $v$ is low, and the search market coexists with the PEA, $\rho \in(0,1)$, when $v$ is high.

\section{Empirical Analysis}

\subsection{German Job Vacancy Survey}

We use the German Job Vacancy Survey, a dataset collected by the Federal Employment Agency in German. The German Job Vacancy Survey is based on a representative sample of establishments, which is newly sampled each year. The yearly survey started in 1989 and was initially conducted to provide an estimate of the total number of vacancies in Germany relative to the number of vacancies registered with the PEA.

The survey includes establishment level data on firm size, number of vacancies, hires and quits in the last 12 months, and information on the industry and region of the firm. The economic conditions of a firm can be proxyed by binary indicator variables for "low sales", "financial constraints", and "not enough suitable employees". It also contains a number of questions concerning the last case of a successfully filled vacancy and if applicable the last case where a recruitment has been abandoned. ${ }^{5}$ In both cases firms are asked to provide information on the qualification and experience level required for the job, on whether the vacancies were registered with the PEA and on whether the firm experienced difficulties in the recruitment process due to "high wage demands" of applicants or because they did not receive "enough suitable applicants". Unfortunately, no data on posted or paid wages is available. In addition, a few interesting questions were not asked in the case where the firm decided to abandon the hiring process. The information on the number of applicants, the number of suitable applicants, and on the search channels used by the firm is only available for those vacancies, which were successful in hiring a worker. The same is true for job characteristics like permanent/temporary, full-/part-time, and weekend-work. We use the years 2005 to 2010, since the information on the number of applicants and the number of suitable applicants is only available since 2005. The data for the years 2011 to 2014 is not yet available.

In total, 83,723 establishments participated in the survey in the years 2005 to $2010.34 .7 \%$ of them did not post a vacancy, $49.8 \%$ posted at least one vacancy and always hired a worker, $10.8 \%$ posted at least one vacancy but were not always successful, and $2.0 \%$ posted a vacancy but were never successful (and $2.7 \%$ did not respond to these questions). In 48,089 cases the establishments responded to ques-

\footnotetext{
${ }^{5}$ The fact that each observation contains a completed (successful or unsuccessful) recruitment process implies that we do not need to worry about selection due to censoring.
} 
tions addressed to successfully filled vacancies and in 6,437 cases to questions addressed to vacancies that were never filled. Since we are interested in the implications of searching in a decentralized market versus the PEA, we exclude those vacancies, where the hiring firm exclusively used a recruitment channel like the internal job market, recommendations by employees, and the selection from former apprentices or interns. This leaves us with 32,104 observations. Further observations had to be dropped because of item non-response. The respective number of observations are reported in the respective tables.

\subsection{Testable predictions}

Our main prediction is that firms, which register their vacancy with the PEA, receive on average a less productive pool of applicants. In our dataset firms report the number of applicants and the number of suitable applicants of their last successful hire. In our theoretical model firms identify with probability $1-\delta$ a low-type worker. Thus, what we observe as fraction of suitable applicants in the data can from the viewpoint of the theory be interpreted as the fraction of applicants that are not detected as being unproductive. It is easy to verify in the theoretical model that the fraction of applicants that are not detected as being unproductive in the decentralized market exceeds the respective fraction in the PEA, i.e.,

$$
\frac{m+(1-m) \delta^{2}}{m+(1-m) \delta}>m+(1-m) \delta .
$$

This inequality also holds if firms use the PEA alongside other search channels, as it is generally the case in the data. We will test this hypothesis in two ways. First, we will investigate the effect of having registered the vacancy with the PEA on the fraction of suitable applicants, an information which is only available for firms that successfully hired a worker. In a second regression we will use all vacancies and investigate the effect of having registered the vacancy with the PEA on the binary variable, which indicates that the firm experienced difficulties in the recruitment process because it did not receive "enough suitable applicants".

Our theory also predicts that firms in the decentralized market offer higher wages compared to firms registered in the PEA. For the empirical test we assume that vacancies that use other search channels alongside the PEA post lower wages in all search channels compared to vacancies that only use search channels associated with the decentralized market. Since we neither observe the posted nor the paid wage, we cannot directly test this hypothesis. We will therefore use the binary variable, which indicates that the firm experienced difficulties in the recruitment process due to "high wage demands" of its applicants. This information is available for successful as well as unsuccessful vacancies. According to our theory we expect that firms that register their vacancy with the PEA report more often, that 
they experience difficulties due to "high wage demands".

\subsection{Identification}

We do not have a natural experiment that would give us truly exogenous variation in the sign-up of vacancies to PEAs. Our dataset, however, provides more information than most other dataests to control for vacancy-level characteristics, which are thought to influence firms decisions to register a vacancy with the PEA. Most importantly, we have information on the skill and occupation level required for the vacant job and can control for job characteristics like permanent/temporary, full-/part-time, and weekend-work. We can also control for firm size as well as the economic condition of the firm as captured by the binary indicator variables "low sales", "financial constraints", and "not enough suitable employees".

It could still be the case that there are unobservable characteristics, which influence a firms' decision to register it's vacancy and which are correlated with the share of suitable applicants or the firms' difficulties caused by "high wage demands". If the unobserved characteristic varies on the industrial or regional level, then this is controlled for by including industry- and region-fixed-effects. One could for example be worried that PEAs in regions with a higher share of less productive unemployed workers have invested more and hence are more efficient in getting vacancies registered. This would, however, be captured by region-fixed-effects. And even if regional characteristics would change over time, e.g. do to the Hartz-reforms or the Great Recession, then this is controlled for by including year-fixed-effects and interaction variables of year- and region-fixed-effects.

We also want to rule out that vacancies, which were unsuccessful in receiving enough suitable applicants or were unsuccessful because of their low wage offer decide to post their vacancy with the PEA in order to increase their chances to attract suitable candidates at the posted wages. To test this reverse causality hypothesis we use information on the intended starting date for the employment relationship and the date at which the firm decided on the applicant it hired. This enables us to exclude all vacancies where the firm decided on the applicant after the intended starting date for the employment relationship. This subsample should therefore no longer include firms, which were unsuccessful in their first recruitment attempt and decided in a second attempt to post their vacancy with the PEA. The fact that our results do not change irrespective of whether we take the whole or the reduced sample indicates that we do not need to worry about reverse causality. 


\subsection{Registered versus unregistered vacancies}

We start with a descriptive analysis comparing registered with unregistered vacancies. We denote those vacancies as registered that among other search channels register their vacancy with the PEA, which includes also registrations on the online platform of the PEA. $47.1 \%$ of all vacancies in our sample are registered with the PEA. The upper part of Table 1 displays the differences with respect to the endogenous variables under consideration. Registered vacancies, which were successful in hiring a worker, have on average 19.9 applicants, whereas unregistered vacancies have on average 21.2 applicants. Among the successful vacancies the fraction of suitable applicants at registered vacancies is $41.4 \%$ and the fraction at unregistered vacancies equals $45.3 \%$. Across all vacancies, i.e., including those which were not successful in hiring a worker, $26.8 \%$ of vacancies, which registered with the PEA, and $15.4 \%$ of vacancies, which did not register, reported that they had difficulties in the recruitment process because they had not enough suitable applicants. A similar tendency can be found with respect to those vacancies reporting difficulties due to high wage demands $(10.0 \%$ of registered vacancies compared to $5.4 \%$ of unregistered vacancies).

Table 1: Differences between registered and unregistered vacancies

\begin{tabular}{lccc}
\hline \hline & & \multicolumn{2}{c}{ registered with the PEA } \\
& all & yes & no \\
\hline \hline number of applicants ${ }^{\text {a) }}$ & 20.6 & 19.9 & 21.2 \\
share of suitable applicants ${ }^{\mathrm{a}}$ ) & $43.4 \%$ & $41.4 \%$ & $45.3 \%$ \\
not enough suitable applicants & $21.0 \%$ & $26.8 \%$ & $15.4 \%$ \\
applicants demand higher wages & $7.6 \%$ & $10.0 \%$ & $5.4 \%$ \\
\hline firm size & 239.8 & 209.4 & 273.8 \\
fraction of low skilled jobs & $9.0 \%$ & $9.7 \%$ & $8.3 \%$ \\
fraction of medium skilled jobs & $69.7 \%$ & $73.1 \%$ & $66.7 \%$ \\
fraction of high skilled jobs & $21.3 \%$ & $17.2 \%$ & $25.0 \%$ \\
fraction of jobs requiring occupation & $49.8 \%$ & $49.7 \%$ & $49.9 \%$ \\
specific experience & & & $6.8 \%$ \\
firms with financial constraints & $8.1 \%$ & $9.6 \%$ & $16.2 \%$ \\
firms with low sales & $17.7 \%$ & $19.4 \%$ & $7.3 \%$ \\
firms with not enough suitable workers & $10.8 \%$ & $14.6 \%$ & \\
\hline \hline
\end{tabular}

Source: German Job Vacancy Survey 2005-2010.

a) Given that the vacancy was successful in hiring a worker. 
The differences reported for the endogenous variables can of course be driven by the differences across firm- and job-characteristics. These are reported at the bottom part of Table 1 and show that establishments that register their vacancies are on average smaller, are more financially constrained, experience low sales and have less suitable employees. Table 1 also shows that registered jobs require less qualification but almost the same occupation specific experience as jobs that are not registered with the PEA.

\subsection{Share of suitable applicants}

The share of suitable applicants among all applicants at registered vacancies is with $41.4 \%$ around 3.9 percentage points lower than the share of suitable applicants at unregistered vacancies. This pattern is confirmed by Figure 1, which shows that the cumulative density distribution for the share of suitable applicants of unregistered vacancies first-order stochastically dominates (is always below) the cumulative density distribution at registered vacancies.

Figure 1: Cumulative distribution of the share of suitable applicants

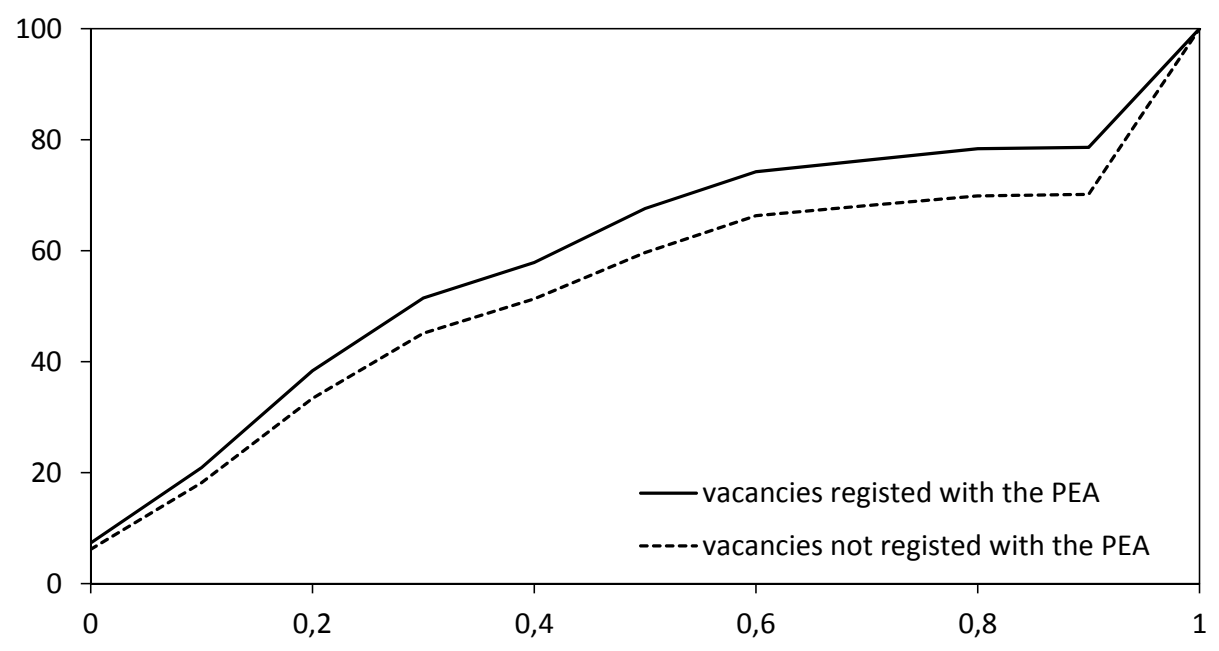

Source: German Job Vacancy Survey 2005-2010.

In Table 2 we control for observable firm- and job-characteristics by including the logarithm of the establishment size, binary indicator variables for the economic condition of the establishment like "low sales", "financial constraints", and "not enough suitable employees", indicator variables for the qualification and occupation specific experience requirements for the job, indicator variables for parttime and temporary jobs and for jobs requiring weekend-work. In addition we include year, industry 
and regional fixed effects. To control for regional time-varying effects we interact the time and regional dummy variables. Table 2 provides the estimated coefficient for the binary indicator variable, which equals 1 if the vacancy is registered with the PEA as well as the indicator variables for the required qualification level. The remaining regression coefficients for firm- and job-characteristics can be found in Table 5 in the Appendix.

Table 2 provides in columns (1) and (2) the OLS estimates for the share of suitable applicants. The dependent variable in columns (3) to (4) is the logarithm of the number of suitable applicants (plus one). To make these results comparable to columns (1) and (2) we include in these regressions the logarithm of the total number of applicants (plus one). The full regression with the coefficients for all firm- and job-characteristics can be found in Table 5 in the Appendix.

Table 2: Suitable applicants (OLS estimates)

\begin{tabular}{lcccc}
\hline \hline & \multicolumn{2}{c}{ OLS (share) } & \multicolumn{2}{c}{ OLS (number) } \\
& $(1)$ & $(2)$ & $(3)$ & $(4)$ \\
\hline \hline PEA & $-0.0524^{* * *}$ & $-0.0552^{* * *}$ & $-0.0447^{* * *}$ & $-0.0461^{* * *}$ \\
& $(0.0041)$ & $(0.0051)$ & $(0.0067)$ & $(0.0085)$ \\
number of applicants & & & $0.5106^{* * *}$ & $0.5266^{* * *}$ \\
& & & $(0.0042)$ & $(0.0052)$ \\
low skill & $0.0364^{* * *}$ & $0.0414^{* * *}$ & 0.0130 & 0.0230 \\
& $(0.0080)$ & $(0.0103)$ & $(0.0127)$ & $(0.0158)$ \\
high skill & $-0.0131^{* *}$ & $-0.0120^{*}$ & $-0.0172^{*}$ & -0.0152 \\
& $(0.0052)$ & $(0.0066)$ & $(0.0088)$ & $(0.0109)$ \\
\hline firm-, job-characteristics & yes & yes & yes & yes \\
year-, region-, industry-FE & yes & yes & yes & yes \\
(year x region)-FE & yes & yes & yes & yes \\
\hline R2 & 0.0866 & 0.0910 & 0.6020 & 0.6207 \\
$\mathrm{~N}$ & 23,146 & 13,731 & 21,926 & 13,731 \\
\hline \hline
\end{tabular}

Source: German Job Vacancy Survey 2005-2010.

Robust standard errors in brackets. ${ }^{* * *}$ indicates $p<0.01 ;{ }^{* *} p<0.05 ;^{*} p<0.1$.

Table 2 presents our first main result: The share of suitable applicants is between 4.5 to 5.5 percentage points lower at vacancies registered with the PEA compared to unregistered vacancies. Given that the share of suitable applicants at unregistered vacancies equals $45.3 \%$ the difference of 4.5 to 5.5 percentage points implies that registered vacancies have on average 10 percent less suitable applicants than vacancies that only use decentralized search channels. This negative correlation between registering a 
vacancy at the PEA and the number of suitable applicants is significant at a $1 \%$ level. Excluding those vacancies where firms agreed on the candidate after the intended start of the employment relationship in order to test for reverse causality does not change the results (see column (2)). The results also hold if the fraction of suitable applicants is replaced by the number of suitable applicants (column (3) and (4)). The coefficients for the qualification requirement in the third and fourth row have the expected sign. They indicate that jobs, which require low skills, have less problems and jobs, which require high skills, have more problems in finding suitable applicants.

In Table 6 in the Appendix we present negative binomial regression coefficient estimates to account for the fact that the number of suitable applicants is a count variable with overdisperson as indicated by the significant $\alpha$-parameters displayed in Table 6 . Our sample only includes vacancies, which were successful in hiring a worker. Since firms with zero suitable applicants are less likely to have successfully hired a worker, the density of zero suitable applicants is systematically biased towards zero. We therefore run as a robustness check a zero-truncated negative binomial regression as well as a negative binomial regression. In both types of regressions the coefficients for the PEA indicator variable are negative, significant at a $1 \%$ level and confirm the results based on the OLS estimates in Table 2.

Since only vacancies, which were successful in hiring a worker, were asked to report the number of total and suitable applicants, we investigate for the whole sample of successful and unsuccessful vacancies whether registered vacancies are more likely to report difficulties in the hiring process, because they had "not enough suitable applicants." Table 3 presents the OLS estimates for the sample of successful vacancies, columns (1), the sample of successful vacancies that agreed on a candidate before the intended starting date of the employment contract, column (2), the sample of unsuccessful vacancies, column (3), and the whole sample column (4). We use the same control variables as in Table 2 with the exception of the job characteristics full-time/part-time, temporary/permanent, weekend-work, since the later are not asked for unsuccessful vacancies. The results in Table 3 supports the results of the OLS estimates presented in Table 2 that establishments, which decided to register their vacancy with the PEA, are confronted with a less suitable pool of applicants. The full regression results can be found in the Appendix in Table 7. The probit estimates, which can be found in Table 8 in the Appendix, are very similar.

The result that the fraction of suitable applicants at vacancies registered with the PEA is about 10 percent lower than at vacancies that only use decentralized search channels is complementary to the empirical evidence on worker self-selection into the PEA based on worker-level data. Using a US household survey Blau and Robins (1990) show that unemployment insurance and welfare recipients are more likely to use the PEA. Using the Canadian Labor Force Survey Osberg (1993) emphasizes the importance to control for sample selection into PEA use. Using the British Labour Force Survey 
Table 3: Difficulty "not enough suitable applicants"

\begin{tabular}{|c|c|c|c|c|}
\hline & \multicolumn{4}{|c|}{ OLS } \\
\hline & successful & successful in time & unsuccessful & all vacancies \\
\hline & (1) & $(2)$ & (3) & (4) \\
\hline \multirow[t]{2}{*}{ PEA } & $0.0787 * * *$ & $0.0583^{* * *}$ & $0.0558^{* *}$ & $0.0912^{* * *}$ \\
\hline & $(0.0053)$ & $(0.0059)$ & $(0.0231)$ & $(0.0056)$ \\
\hline \multirow[t]{2}{*}{ low skill } & $-0.0455^{* * *}$ & $-0.0435^{* * *}$ & -0.0663 & $-0.0428^{* * *}$ \\
\hline & $(0.0086)$ & $(0.0091)$ & $(0.0436)$ & $(0.0092)$ \\
\hline \multirow[t]{2}{*}{ high skill } & $0.0531 * * *$ & $0.0347^{* * *}$ & $0.0456^{*}$ & $0.0781^{* * *}$ \\
\hline & $(0.0070)$ & $(0.0075)$ & $(0.0272)$ & $(0.0073)$ \\
\hline firm-, job-characteristics & yes & yes & yes & yes \\
\hline year-, region-, industry-FE & yes & yes & yes & yes \\
\hline (year $\mathrm{x}$ region)-FE & yes & yes & yes & yes \\
\hline $\mathrm{R} 2$ & 0.0782 & 0.0626 & 0.0790 & 0.0930 \\
\hline $\mathrm{N}$ & 17,959 & 10,918 & 2,023 & 19,982 \\
\hline
\end{tabular}

Source: German Job Vacancy Survey 2005-2010.

Robust standard errors in brackets. *** indicates $p<0.01 ;{ }^{* *} p<0.05 ;{ }^{*} p<0.1$.

Gregg and Wadsworth (1996) find that PEA use is highest among less skilled and long-term unemployed workers. Holzer (1988) uses the Youth Cohort of the National Longitudinal Survey to analyze the self-selection of workers and concludes that PEAs are primarily used by individuals with few job opportunities.

Our analysis is the first to provide evidence that the same type of worker self-selection can also be found among applicants. This is important, because the worker-based evidence in the literature mentioned above does not necessarily imply our result. For example, it could be that the PEA can detect low type workers and sorts them out. This would imply that registered firms receive more applications from suitable workers. The fact that our results show the opposite, i.e., that registered firms receive more applications from less suitable applicants, implies that the PEA is not able to screen workers efficiently enough to ensure that the applicants they allocate are on average as suitable as the workers that apply through the private market. 


\subsection{Difficulties due to "high wage demands"}

Let us finally investigate whether we can also find evidence that the job-brokering mechanism inherent in PEAs leads to lower wage offers for workers that find their jobs through the PEA. The German Job Vacancy Survey contains information on whether a firm had difficulties in filling the vacancy because of higher wage demands by its applicants. This information is not only able to shed light into the question on whether registered firms offer lower wages than unregistered firms. It also provides information on whether workers receive different wage offers from registered firms compared to unregistered firms, because workers that demand higher wages will only do so, if they can get a higher offer somewhere else.

If our theory is correct, then vacancies registered with the PEA should be more likely to experience such difficulties. The respective variable is available for successful and unsuccessful vacancies. We use the same control variables as in Table 3. The full set of coefficients can be found in Table 9 in the Appendix and respective probit estimates can be found in Table 10 in the Appendix.

Table 4: Difficulty "high wage demands"

\begin{tabular}{lcccc}
\hline \hline & & & \\
& & & \\
& SLC & \\
& successful & successful in time & unsuccessful & all vacancies \\
\hline \hline PEA & $0.0306^{* * *}$ & $0.0217^{* * *}$ & 0.0236 & $0.0347^{* * *}$ \\
& $(0.0029)$ & $(0.0031)$ & $(0.0216)$ & $(0.0031)$ \\
low skill & $0.0197^{* * *}$ & $0.0109^{*}$ & 0.0419 & $0.0215^{* * *}$ \\
& $(0.0057)$ & $(0.0063)$ & $(0.0395)$ & $(0.0060)$ \\
high skill & $0.0069^{* *}$ & 0.0031 & $0.0546^{* *}$ & $0.0198^{* * *}$ \\
& $(0.0035)$ & $(0.0035)$ & $(0.0259)$ & $(0.0039)$ \\
firm-, job-characteristics & yes & yes & yes & yes \\
year-, region-, industry-FE & yes & yes & yes & yes \\
(year x region)-FE & yes & yes & yes & yes \\
\hline R2 & 0.0457 & 0.0405 & 0.0907 & 0.0558 \\
$\mathrm{~N}$ & 27,554 & 16,780 & 2,023 & 29,577 \\
\hline \hline
\end{tabular}

Source: German Job Vacancy Survey 2005-2010.

Robust standard errors in brackets. *** indicates $p<0.01$; ** $p<0.05 ;{ }^{*} p<0.1$.

The results in Table 4 indicate a strong positive correlation between registering a vacancy with the PEA and experiencing difficulties in the recruitment process due to high wage demands by applicants. The coefficients of the PEA indicator variable for the sample of successfully filled vacancies are signifi- 
cant at a $1 \%$ level (column (1)). This also holds, if we exclude all those observations where firms agreed on an applicant after the intended starting date of the employment contract (column (2)). The coefficient for the unsuccessful vacancies is statistically insignificant (column (3)), but has the same sign and is similar in magnitude. The insignificance might be due to the relatively small sample size of around 2,000 observations in the case of unsuccessful vacancies compared to more than 27,000 observations in the case of successfully filled vacancies. The coefficient for the whole sample is again significant at a $1 \%$ level (column (4)).

Our evidence indirectly supports the hypothesis that firms, which register their vacancy with the PEA, offer lower wages than firms, which did not register their vacancy. It also implies residual wage dispersion, which differs systematically depending on whether the vacancy is registered with the PEA or not. This is in line with our theory, which suggests that the job-brokering activity and its competition reducing effect are responsible for lower wages offers at PEAs. Our evidence is therefore in line with the literature that finds a persistent lower wages paid to workers that found their job via the PEA after controlling for worker characteristics like Holzer (1988) for the US and Addison and Protugal (2002) for Portugal. Our theory suggests that the job-brokering activity and its competition reducing effect are responsible for the fact that vacancies registered at the PEAs offer lower wages.

\section{Conclusion}

In order to understand the functioning of labor markets in the presence of the PEA, we develop a simple theory and empirically test its predictions. Our model allows firms to choose between two alternative methods of finding a worker; the search market, where the individual applications are subject to coordination frictions, and the PEA. Searching in the decentralized market is costly for workers, so firms in the decentralized market have to post higher wages than firms registered with the PEA in order to attract workers. Since the value of searching in the private market is higher for high productivity workers, firms in the private market are able to attract a better pool of applicants. Registered firms have no incentive to compete with firms in the decentralized market by offering the same wage, since the job-brokering service of the PEA provides a wage-offer-independent meeting technology for firms.

We use the German Job Vacancy Survey to investigate the predictions of our theory. We find that the fraction of suitable applicants at vacancies registered with the PEA is about 10 percent lower than at vacancies that only use decentralized search channels. We also find support for the hypothesis that firms, which register their vacancy with the PEA, offer lower wages than firms that did not register their vacancy.

An interesting topic for future research would be to assess the effect of labor market reforms, e.g. 
the so-called Hartz Reform in Germany. Part of the reforms package (Hartz III) aims at restructuring the Public Employment Agency. One issue would be to study whether the crowding out effect studied by Pissarides (1979) has been sustained - more efficient PEAs crowd out private search effort. To evaluate this effect in the context of the Hartz Reform, it would be necessary to extend the model and data to incorporate other parts of the reform - creating new types of employment opportunities (Hartz I), introducing additional wage subsidies (Hartz II), and cutting the unemployment benefits for the long-term unemployed (Hartz IV). We believe our framework will best fit to study this and other related issues, e.g. the effect on the wage inequality, of such a reform policy.

\section{Appendix}

Proof of $\Pi_{a}(x)>\Pi_{a}^{\prime}$

Using (3) and (4) simplifies the inequality in question to $\Pi_{a}(x)>\Pi_{a}^{\prime} \Longleftrightarrow m\left(1-c^{m} \eta(x)\right)>m(1-w)-$ $(1-m) \delta w$

$$
\begin{aligned}
& \Longleftrightarrow m\left(1-\frac{m}{m+(1-m) \delta^{2}} \frac{e^{-x}\left(1-e^{-x}\right)}{x}\right)>m-(m+(1-m) \delta) \frac{m}{m+(1-m) \delta^{2}} \frac{x e^{-x}}{1-e^{-x}} \\
& \Longleftrightarrow(m+(1-m) \delta) \frac{x}{1-e^{-x}}-m \frac{1-e^{-x}}{x}>0,
\end{aligned}
$$

where the last inequality follows from $\frac{x}{1-e^{-x}}>\frac{1-e^{-x}}{x} \Longleftrightarrow 1>\eta(x)^{2}$.

\section{Proof of Theorem 1}

Define $\Gamma \equiv \frac{1}{m}\left\{\Pi_{s}(x)-\Pi_{a}(x)\right\}$ for $x \in[0, \infty)$, where by (1) and (4), $x=x(\rho)$ is determined by

$$
\frac{e^{-x}}{x}=\frac{m+(1-m) \delta^{2}}{m+(1-m) \delta} \frac{v(1-\rho)}{m}
$$

This expression shows that $x(\rho)$ is strictly increasing in $\rho \in[0,1)$ and satisfies $x(0) \equiv \underline{x} \in(0, \infty)$ and $x(\rho) \rightarrow \infty$ as $\rho \rightarrow 1$.

In what follows, we use the implicit function $\Gamma$ to show the existence and uniqueness of an equilibrium $\rho \in[0,1)$. There are two possible cases. Suppose in equilibrium $a>v \rho$. This implies $\rho \in[0, \bar{\rho})$ where $\bar{\rho} \equiv \min \left\{\frac{a}{v}, 1\right\}$. Then, $\Gamma=\Gamma(x)$ where

$$
\Gamma(x)=\frac{1-e^{-x}-x e^{-x}}{m+(1-m) \delta}-1+\frac{m}{m+(1-m) \delta^{2}} \frac{e^{-x}\left(1-e^{-x}\right)}{x} .
$$

Observe that: $\Gamma(0)=-1+\frac{m}{m+(1-m) \delta^{2}}<0 ; \Gamma(x) \rightarrow \frac{1}{m+(1-m) \delta}-1>0$ as $x \rightarrow \infty$. Hence, since $\Gamma(x)$ is 
continuous in $x \in[0, \infty)$, there exists an $x^{*} \in(0, \infty)$ that satisfies $\Gamma\left(x^{*}\right)=0$. Observe further that

$$
\begin{aligned}
& \left.\frac{d \Gamma(x)}{d x}\right|_{x=x^{*}} \\
& =\frac{x e^{-x}}{m+(1-m) \delta}-\left.\frac{m}{m+(1-m) \delta^{2}} \frac{e^{-x}}{x^{2}}\left[(x+1)\left(1-e^{-x}\right)-x e^{-x}\right]\right|_{x=x^{*}} \\
& =\frac{x^{*} e^{-x^{*}}}{1-e^{-x^{*}}-x^{*} e^{-x^{*}}} \\
& -\frac{m}{m+(1-m) \delta^{2}} \frac{e^{-x^{*}}}{1-e^{-x^{*}}-x^{*} e^{-x^{*}}}\left[\left(1-\frac{1-e^{-x^{*}}}{x^{*}}\right) e^{-x^{*}}+\left(\frac{1-e^{-x^{*}}}{x^{*}}-e^{-x^{*}}\right)\left(x^{*}+1\right) \frac{1-e^{-x^{*}}}{x^{*}}\right] \\
& >\frac{e^{-x^{*}}}{1-e^{-x^{*}}-x^{*} e^{-x^{*}}}\left[x^{*}-\left(1-\frac{1-e^{-x^{*}}}{x^{*}}\right) e^{-x^{*}}-\left(\frac{1-e^{-x^{*}}}{x^{*}}-e^{-x^{*}}\right)\left(x^{*}+1\right) \frac{1-e^{-x^{*}}}{x^{*}}\right] \\
& =\frac{e^{-x^{*}}}{1-e^{-x^{*}}-x^{*} e^{-x^{*}}}\left[\frac{\left(x^{*}+1-e^{-x^{*}}\right)^{2}}{x^{*}}-\frac{\left(1-e^{-x^{*}}-x^{*} e^{-x^{*}}\right)^{2}}{x^{* 2}}\right] \\
& >0 \text {. }
\end{aligned}
$$

In the above, we use $\Gamma\left(x^{*}\right)=0 \Leftrightarrow \frac{x^{*} e^{-x^{*}}}{m+(1-m) \delta}=\frac{x^{*} e^{-x^{*}}}{1-e^{-x^{*}}-x^{*} e^{-x^{*}}}\left[1-\frac{m}{m+(1-m) \delta^{2}} \frac{e^{-x^{*}}\left(1-e^{-x^{*}}\right)}{x^{*}}\right]$ in the second equality, and $x+1-e^{-x}>\frac{1-e^{-x}}{x}-e^{-x}$ and $x+1-e^{-x}>1-e^{-x}-x e^{-x}$ in the last inequality. Since $\Gamma(0)<0<\Gamma(\infty), \frac{d \Gamma}{d x}>0$ at $x=x^{*}$ implies $x^{*} \in(0, \infty)$ is unique (that is, $\Gamma(x)$ curve cannot cross the line $\Gamma(x)=0$ more than once).

Finally, notice that the $x^{*} \in(0, \infty)$ satisfying $\Gamma\left(x^{*}\right)=0$ determined above does not depend on $v$, whereas $\underline{x}(\equiv x(0))$ determined by $(10)$ is strictly decreasing in $v$. Hence, we have $x^{*}>\underline{x} \Leftrightarrow v>v * \equiv$ $\frac{m+(1-m) \delta}{m+(1-m) \delta^{2}} \frac{m}{x^{*}} e^{-x^{*}}$. On the other hand, denote by $\bar{x}$ the solution of $x=x(\rho)$ to (10) as $\rho \rightarrow \bar{\rho}$. If $\frac{a}{v} \geq 1$ then $\bar{\rho}=1$ and $\bar{x}=\infty$, so $x^{*}<\bar{x}$. If $\frac{a}{v}<1$ then $\bar{\rho}=\frac{a}{v}<1$ and $\bar{x}<\infty$, so $x^{*}<\bar{x}$ if and only if $v<v^{*}+a$. The very last inequality follows, by (10), from

$$
\frac{e^{-\bar{x}}}{\bar{x}}-\frac{e^{-x^{*}}}{x^{*}}=\frac{m+(1-m) \gamma^{2}}{(m+(1-m) \gamma) m}\left(v-a-v^{*}\right) .
$$

which implies

$$
x^{*}<\bar{x} \Longleftrightarrow \frac{e^{-\bar{x}}}{\bar{x}}<\frac{e^{-x^{*}}}{x^{*}} \Longleftrightarrow v<v^{*}+a .
$$

To sum up, there exists a unique $\rho \in(0, \bar{\rho})$ that satisfies $\frac{e^{-x^{*}}}{x^{*}}=\frac{m+(1-m) \delta^{2}}{m+(1-m) \delta} \frac{v(1-\rho)}{m}$ (and hence $\left.\Pi_{s}\left(x^{*}\right)=\Pi_{a}\left(x^{*}\right)\right)$ if and only if $v \in\left(v^{*}, v^{*}+a\right)$, and $\rho=0$, satisfying $\Pi_{s}\left(x^{*}\right)>\Pi_{a}\left(x^{*}\right)$, if and only if $v \in\left(0, v^{*}\right)$

Suppose next in equilibrium $a \leq v \rho$. This implies $\rho \in[\bar{\rho}, 1)$, where $\bar{\rho} \equiv \min \left\{\frac{a}{v}, 1\right\}$, and is possible only when $\frac{a}{v}<1$. Then, $\Gamma=\Gamma(\rho, x)$ where

$$
\Gamma(\rho, x)=\frac{1-e^{-x}-x e^{-x}}{m+(1-m) \delta}-\frac{a}{\rho v}\left[1-\frac{m}{m+(1-m) \delta^{2}} \frac{e^{-x}\left(1-e^{-x}\right)}{x}\right],
$$

where $x=x(\rho)$ is determined by (10) as before. Observe that:

$$
\Gamma(\bar{\rho}, \bar{x})=\frac{1-e^{-\bar{x}}-\bar{x} e^{-\bar{x}}}{m+(1-m) \delta}-\left[1-\frac{m}{m+(1-m) \delta^{2}} \frac{e^{-\bar{x}}\left(1-e^{-\bar{x}}\right)}{\bar{x}}\right] \leq 0,
$$

if and only if $v \geq v^{*}+a$ (see above that $\Gamma(\bar{\rho}, \bar{x})=\Gamma(\bar{x})<0$ for $\left.v \geq v^{*}+a\right) ; \Gamma(\rho, x) \rightarrow \frac{1}{m+(1-m) \delta}-\frac{a}{v}>0$ as $\rho \rightarrow 1$. Hence, since $\Gamma(\cdot)$ is continuous in $\rho \in[\bar{\rho}, 1)$, there exists an $\rho^{*} \in[\bar{\rho}, 1)$ that satisfies $\Gamma\left(\rho^{*}, x\left(\rho^{*}\right)\right)=0$ if and only if $v \geq v^{*}+a$. Observe further that

$$
\left.\frac{d \Gamma(\cdot)}{d \rho}\right|_{\rho=\rho^{*}}=\frac{\partial \Gamma(\cdot)}{\partial \rho}+\left.\frac{d x}{d \rho} \frac{\partial \Gamma(\cdot)}{\partial x}\right|_{\rho=\rho^{*}},
$$


where $\frac{\partial \Gamma(\cdot)}{\partial \rho}=\frac{a}{\rho^{2} v}\left[1-\frac{m}{m+(1-m) \delta^{2}} \frac{e^{-x}\left(1-e^{-x}\right)}{x}\right]>0, \frac{d x}{d \rho}>0$ (by $\left.(10)\right)$, and

$$
\left.\frac{\partial \Gamma(\cdot)}{\partial x}\right|_{\rho=\rho^{*}}>\left.\frac{a}{\rho v} \frac{e^{-x}}{1-e^{-x}-x e^{-x}}\left[\frac{\left(x+1-e^{-x}\right)^{2}}{x}-\frac{\left(1-e^{-x}-x e^{-x}\right)^{2}}{x^{2}}\right]\right|_{\rho=\rho^{*}}>0,
$$

which follows from exactly the procedure developed above to show $\left.\frac{d \Gamma(x)}{d x}\right|_{x=x^{*}}>0$ in (11). Therefore, $\rho^{*} \in[\bar{\rho}, 1)$ that satisfies $\Gamma\left(\rho^{*}, x\left(\rho^{*}\right)\right)=0$ is unique given $v \geq v^{*}+a$.

Combining with the previous result, we have shown that there exist a unique $\rho \in(0,1)$ if and only if $v>v^{*}$, and $\rho=0$ if and only if $v \leq v^{*}$. This completes the proof of Theorem 1 . 


\section{Further regression results}

Table 5: Suitable applicants (OLS estimates)

\begin{tabular}{|c|c|c|c|c|}
\hline & \multicolumn{2}{|c|}{ OLS (share) } & \multicolumn{2}{|c|}{ OLS (number) } \\
\hline & (1) & $(2)$ & (3) & $(4)$ \\
\hline PEA & $\begin{array}{c}-0.0524 * * * \\
(0.0041)\end{array}$ & $\begin{array}{c}-0.0552^{* * *} \\
(0.0051)\end{array}$ & $\begin{array}{c}-0.0447^{* * *} \\
(0.0067)\end{array}$ & $\begin{array}{c}-0.0461^{* * *} \\
(0.0085)\end{array}$ \\
\hline number of applicants & & & $\begin{array}{c}0.5106^{* * *} \\
(0.0042)\end{array}$ & $\begin{array}{c}0.5266^{* * *} \\
(0.0052)\end{array}$ \\
\hline low skill & $\begin{array}{c}0.0364^{* * *} \\
(0.0080)\end{array}$ & $\begin{array}{c}0.0414^{* * *} \\
(0.0103)\end{array}$ & $\begin{array}{c}0.0130 \\
(0.0127)\end{array}$ & $\begin{array}{c}0.0230 \\
(0.0158)\end{array}$ \\
\hline high skill & $\begin{array}{c}-0.0131^{* *} \\
(0.0052)\end{array}$ & $\begin{array}{c}-0.0120^{*} \\
(0.0066)\end{array}$ & $\begin{array}{c}-0.0172^{*} \\
(0.0088)\end{array}$ & $\begin{array}{l}-0.0152 \\
(0.0109)\end{array}$ \\
\hline occup. experience required & $\begin{array}{c}-0.0443^{* * *} \\
(0.0041)\end{array}$ & $\begin{array}{c}-0.0425^{* * *} \\
(0.0052)\end{array}$ & $\begin{array}{c}-0.0671^{* * *} \\
(0.0067)\end{array}$ & $\begin{array}{c}-0.0658^{* * *} \\
(0.0084)\end{array}$ \\
\hline permanent contract & $\begin{array}{c}-0.0415^{* * *} \\
(0.0042)\end{array}$ & $\begin{array}{c}-0.0390^{* * *} \\
(0.0053)\end{array}$ & $\begin{array}{c}-0.0356^{* * *} \\
(0.0070)\end{array}$ & $\begin{array}{c}-0.0317^{* * *} \\
(0.0087)\end{array}$ \\
\hline full-time & $\begin{array}{c}-0.0399 * * * \\
(0.0057)\end{array}$ & $\begin{array}{c}-0.0350^{* * *} \\
(0.0069)\end{array}$ & $\begin{array}{c}-0.0455^{* * *} \\
(0.0089)\end{array}$ & $\begin{array}{c}-0.0400^{* * *} \\
(0.0107)\end{array}$ \\
\hline weekend-work & $\begin{array}{c}0.0192^{* * *} \\
(0.0060)\end{array}$ & $\begin{array}{c}0.0082 \\
(0.0074)\end{array}$ & $\begin{array}{c}0.0069 \\
(0.0094)\end{array}$ & $\begin{array}{c}0.0067 \\
(0.0115)\end{array}$ \\
\hline firm size (ln) & $\begin{array}{c}-0.0057^{* * *} \\
(0.0014)\end{array}$ & $\begin{array}{c}-0.0052^{* * *} \\
(0.0018)\end{array}$ & $\begin{array}{c}0.0318^{* * *} \\
(0.0025)\end{array}$ & $\begin{array}{c}0.0298^{* * *} * \\
(0.0031)\end{array}$ \\
\hline "financial constraints" & $\begin{array}{l}0.0135^{*} \\
(0.0077)\end{array}$ & $\begin{array}{l}0.0194^{*} \\
(0.0100)\end{array}$ & $\begin{array}{c}0.0058 \\
(0.0125)\end{array}$ & $\begin{array}{c}0.0090 \\
(0.0165)\end{array}$ \\
\hline "low sales" & $\begin{array}{c}0.0123^{* *} \\
(0.0056)\end{array}$ & $\begin{array}{l}0.0132^{*} \\
(0.0073)\end{array}$ & $\begin{array}{c}0.0041 \\
(0.0089)\end{array}$ & $\begin{array}{c}0.0030 \\
(0.0116)\end{array}$ \\
\hline "not enough suitable empl." & $\begin{array}{c}-0.0500^{* * *} \\
(0.0069)\end{array}$ & $\begin{array}{c}-0.0509^{* * *} \\
(0.0100)\end{array}$ & $\begin{array}{c}-0.1505^{* * *} \\
(0.0113)\end{array}$ & $\begin{array}{c}-0.1558^{* * *} \\
(0.0165)\end{array}$ \\
\hline year-, region-, industry-FE & yes & yes & yes & yes \\
\hline (year $\mathrm{x}$ region)-FE & yes & yes & yes & yes \\
\hline $\mathrm{R} 2$ & 0.0883 & 0.0910 & 0.6020 & 0.6207 \\
\hline $\mathrm{N}$ & 21,926 & 13,731 & 21,926 & 13,731 \\
\hline
\end{tabular}

Source: German Job Vacancy Survey 2005-2010.

Robust standard errors in brackets. ${ }^{* * *}$ indicates $p<0.01{ }^{* *} p<0.05 ;{ }^{*} p<0.1$. 
Table 6: Suitable applicants (negative binomial estimates)

\begin{tabular}{|c|c|c|c|c|}
\hline & \multicolumn{2}{|c|}{ zero-truncated negative binomial } & \multicolumn{2}{|c|}{ negative binomial } \\
\hline & (1) & $(2)$ & $(3)$ & $(4)$ \\
\hline PEA & $\begin{array}{c}-0.0422^{* * *} \\
(0.0125)\end{array}$ & $\begin{array}{c}-0.0467^{* * *} \\
(0.0150)\end{array}$ & $\begin{array}{c}-0.0428 * * * \\
(0.0107)\end{array}$ & $\begin{array}{c}-0.0467^{* * *} \\
(0.0130)\end{array}$ \\
\hline number of applicants & $\begin{array}{c}0.9284^{* * *} \\
(0.0074)\end{array}$ & $\begin{array}{c}0.9171^{* * * *} \\
(0.0088)\end{array}$ & $\begin{array}{c}0.7522^{* * *} \\
(0.0062)\end{array}$ & $\begin{array}{c}0.7555^{* * *} \\
(0.0073)\end{array}$ \\
\hline low skill & $\begin{array}{c}0.0739 * * * \\
(0.0239)\end{array}$ & $\begin{array}{c}0.0779 * * * \\
(0.0291)\end{array}$ & $\begin{array}{c}0.0650^{* * *} \\
(0.0200)\end{array}$ & $\begin{array}{c}0.0687^{* * *} \\
(0.0243)\end{array}$ \\
\hline high skill & $\begin{array}{c}-0.0350^{* *} \\
(0.0157)\end{array}$ & $\begin{array}{l}-0.0226 \\
(0.0189)\end{array}$ & $\begin{array}{c}-0.0274^{* *} \\
(0.0137)\end{array}$ & $\begin{array}{l}-0.0197 \\
(0.0165)\end{array}$ \\
\hline occup. experience required & $\begin{array}{c}-0.1260 * * * \\
(0.0126)\end{array}$ & $\begin{array}{c}-0.1254^{* * *} \\
(0.0150)\end{array}$ & $\begin{array}{c}-0.1098 * * * \\
(0.0107)\end{array}$ & $\begin{array}{c}-0.1086^{* * *} \\
(0.0128)\end{array}$ \\
\hline permanent contract & $\begin{array}{c}-0.0760 * * * \\
(0.0128)\end{array}$ & $\begin{array}{c}-0.0752^{* * *} \\
(0.0154)\end{array}$ & $\begin{array}{c}-0.0605^{* * *} \\
(0.0110)\end{array}$ & $\begin{array}{c}-0.0599 * * * \\
(0.0132)\end{array}$ \\
\hline full-time & $\begin{array}{c}-0.0916 * * * \\
(0.0160)\end{array}$ & $\begin{array}{c}-0.0799 * * * \\
(0.0185)\end{array}$ & $\begin{array}{c}-0.0711^{* * *} \\
(0.0139)\end{array}$ & $\begin{array}{c}-0.0620 * * * \\
(0.0161)\end{array}$ \\
\hline weekend-work & $\begin{array}{c}0.0380^{* *} \\
(0.0181)\end{array}$ & $\begin{array}{c}0.0271 \\
(0.0213)\end{array}$ & $\begin{array}{c}0.0283^{*} \\
(0.0148)\end{array}$ & $\begin{array}{c}0.0220 \\
(0.0177)\end{array}$ \\
\hline firm size $(\ln )$ & $\begin{array}{c}0.0484^{* * *} \\
(0.0044)\end{array}$ & $\begin{array}{c}0.0478^{* * *} \\
(0.0053)\end{array}$ & $\begin{array}{c}0.0413^{* * *} \\
(0.0038)\end{array}$ & $\begin{array}{c}0.0407^{* * *} \\
(0.0046)\end{array}$ \\
\hline "financial constraints" & $\begin{array}{c}0.0236 \\
(0.0236)\end{array}$ & $\begin{array}{c}0.0230 \\
(0.0291)\end{array}$ & $\begin{array}{c}0.0252 \\
(0.0203)\end{array}$ & $\begin{array}{c}0.0358 \\
(0.0256)\end{array}$ \\
\hline "low sales" & $\begin{array}{c}0.0131 \\
(0.0178)\end{array}$ & $\begin{array}{c}0.0121 \\
(0.0225)\end{array}$ & $\begin{array}{c}0.0124 \\
(0.0146)\end{array}$ & $\begin{array}{c}0.0144 \\
(0.0185)\end{array}$ \\
\hline "not enough suitable empl." & $\begin{array}{c}-0.2874^{* * *} \\
(0.0251)\end{array}$ & $\begin{array}{c}-0.2958^{* * *} \\
(0.0363)\end{array}$ & $\begin{array}{c}-0.2177^{* * *} \\
(0.0194)\end{array}$ & $\begin{array}{c}-0.2272^{* * *} \\
(0.0280)\end{array}$ \\
\hline$\alpha$-parameter & $\begin{array}{c}0.3575 * * * \\
(0.0072)\end{array}$ & $\begin{array}{c}0.3348^{* * *} \\
(0.0082)\end{array}$ & $\begin{array}{c}0.2336^{* * *} \\
(0.0041)\end{array}$ & $\begin{array}{c}0.2251^{* * *} \\
(0.0049)\end{array}$ \\
\hline year-, region-, industry-FE & yes & yes & yes & yes \\
\hline (year $\mathrm{x}$ region)-FE & yes & yes & yes & yes \\
\hline $\mathrm{R} 2$ & 0.0866 & 0.0910 & 0.6020 & 0.6207 \\
\hline $\mathrm{N}$ & 23,146 & 13,731 & 21,926 & 13,731 \\
\hline
\end{tabular}

Source: German Job Vacancy Survey 2005-2010.

Robust standard errors in brackets. ${ }^{* * *}$ indicates $p<0.01 ; * * p<0.05 ;{ }^{*} p<0.1$. 
Table 7: Difficulty "not enough suitable applicants"

\begin{tabular}{|c|c|c|c|c|}
\hline & \multicolumn{4}{|c|}{ OLS } \\
\hline & successful & successful in time & unsuccessful & all vacancies \\
\hline PEA & $\begin{array}{c}0.0787^{* * *} \\
(0.0053)\end{array}$ & $\begin{array}{c}0.0583^{* * *} \\
(0.0059)\end{array}$ & $\begin{array}{c}0.0558^{* *} \\
(0.0231)\end{array}$ & $\begin{array}{c}0.0912^{* * *} \\
(0.0056)\end{array}$ \\
\hline low skill & $\begin{array}{c}-0.0455^{* * *} \\
(0.0086)\end{array}$ & $\begin{array}{c}-0.0435^{* * *} \\
(0.0091)\end{array}$ & $\begin{array}{l}-0.0663 \\
(0.0436)\end{array}$ & $\begin{array}{c}-0.0428^{* * *} \\
(0.0092)\end{array}$ \\
\hline high skill & $\begin{array}{c}0.0531^{* * * *} \\
(0.0070)\end{array}$ & $\begin{array}{c}0.0347^{* * *} \\
(0.0075)\end{array}$ & $\begin{array}{l}0.0456^{*} \\
(0.0272)\end{array}$ & $\begin{array}{c}0.0781^{* * *} \\
(0.0073)\end{array}$ \\
\hline occup. experience required & $\begin{array}{c}0.0129 * * \\
(0.0053)\end{array}$ & $\begin{array}{l}-0.0002 \\
(0.0057)\end{array}$ & $\begin{array}{c}0.0217 \\
(0.0246)\end{array}$ & $\begin{array}{c}-0.0320 * * * \\
(0.0055)\end{array}$ \\
\hline firm size (ln) & $\begin{array}{c}-0.0049 * * * \\
(0.0018)\end{array}$ & $\begin{array}{c}-0.0054^{* * *} \\
(0.0020)\end{array}$ & $\begin{array}{c}0.0287^{* * * *} \\
(0.0080)\end{array}$ & $\begin{array}{c}-0.0046^{* *} \\
(0.0019)\end{array}$ \\
\hline "financial constraints" & $\begin{array}{l}-0.0121 \\
(0.0107)\end{array}$ & $\begin{array}{c}-0.0208^{*} \\
(0.0114)\end{array}$ & $\begin{array}{l}-0.0319 \\
(0.0355)\end{array}$ & $\begin{array}{l}-0.0043 \\
(0.0111)\end{array}$ \\
\hline "low sales" & $\begin{array}{c}0.0049 \\
(0.0076)\end{array}$ & $\begin{array}{l}-0.0034 \\
(0.0084)\end{array}$ & $\begin{array}{l}-0.0298 \\
(0.0265)\end{array}$ & $\begin{array}{c}0.0075 \\
(0.0078)\end{array}$ \\
\hline "not enough suitable empl." & $\begin{array}{c}0.2188^{* * *} * \\
(0.0119)\end{array}$ & $\begin{array}{c}0.1717^{* * * *} \\
(0.0167)\end{array}$ & $\begin{array}{c}0.0923^{* * *} \\
(0.0243)\end{array}$ & $\begin{array}{c}0.2504^{* * *} \\
(0.0108)\end{array}$ \\
\hline year-, region-, industry-FE & yes & yes & yes & yes \\
\hline (year $\mathrm{x}$ region)-FE & yes & yes & yes & yes \\
\hline $\mathrm{R} 2$ & 0.0782 & 0.0626 & 0.0790 & 0.0930 \\
\hline $\mathrm{N}$ & 17,959 & 10,918 & 2,023 & 19,982 \\
\hline
\end{tabular}

Source: German Job Vacancy Survey 2005-2010.

Robust standard errors in brackets. ${ }^{* * *}$ indicates $p<0.01 ;{ }^{* *} p<0.05$; $^{*} p<0.1$. 
Table 8: Difficulty "not enough suitable applicants"

\begin{tabular}{|c|c|c|c|c|}
\hline & \multicolumn{4}{|c|}{ Probit } \\
\hline & successful & successful in time & unsuccessful & all vacancies \\
\hline PEA & $\begin{array}{c}0.3664^{* * *} \\
(0.0245)\end{array}$ & $\begin{array}{c}0.3580^{* * *} \\
(0.0350)\end{array}$ & $\begin{array}{c}0.1502^{* *} \\
(0.0625)\end{array}$ & $\begin{array}{c}0.3654^{* * *} \\
(0.0218)\end{array}$ \\
\hline low skill & $\begin{array}{c}-0.2313^{* * *} \\
(0.0472)\end{array}$ & $\begin{array}{c}-0.3114^{* * *} \\
(0.0746)\end{array}$ & $\begin{array}{l}-0.1787 \\
(0.1125)\end{array}$ & $\begin{array}{c}-0.1812^{* * *} \\
(0.0416)\end{array}$ \\
\hline high skill & $\begin{array}{c}0.2510^{* * *} \\
(0.0305)\end{array}$ & $\begin{array}{c}0.2242^{* * *} \\
(0.0430)\end{array}$ & $\begin{array}{l}0.1285^{*} \\
(0.0753)\end{array}$ & $\begin{array}{c}0.3087^{* * *} \\
(0.0268)\end{array}$ \\
\hline occup. experience required & $\begin{array}{c}0.0631^{* * *} \\
(0.0241)\end{array}$ & $\begin{array}{c}0.0063 \\
(0.0347)\end{array}$ & $\begin{array}{c}0.0572 \\
(0.0668)\end{array}$ & $\begin{array}{c}0.1292^{* * *} \\
(0.0216)\end{array}$ \\
\hline firm size (ln) & $\begin{array}{c}-0.0230 * * * \\
(0.0085)\end{array}$ & $\begin{array}{c}-0.0337^{* * *} \\
(0.0123)\end{array}$ & $\begin{array}{c}0.0827^{* * *} \\
(0.0223)\end{array}$ & $\begin{array}{c}-0.0192^{* *} \\
(0.0076)\end{array}$ \\
\hline "financial constraints" & $\begin{array}{l}-0.0352 \\
(0.0473)\end{array}$ & $\begin{array}{l}-0.1126 \\
(0.0713)\end{array}$ & $\begin{array}{l}-0.0899 \\
(0.0935)\end{array}$ & $\begin{array}{l}-0.0021 \\
(0.0405)\end{array}$ \\
\hline "low sales" & $\begin{array}{c}0.0233 \\
(0.0322)\end{array}$ & $\begin{array}{l}-0.0257 \\
(0.0486)\end{array}$ & $\begin{array}{l}-0.0840 \\
(0.0703)\end{array}$ & $\begin{array}{c}0.0301 \\
(0.0283)\end{array}$ \\
\hline "not enough suitable empl." & $\begin{array}{c}0.7245^{* * *} * \\
(0.0347)\end{array}$ & $\begin{array}{c}0.7093^{* * *} \\
(0.0555)\end{array}$ & $\begin{array}{c}0.2623^{* * *} \\
(0.0676)\end{array}$ & $\begin{array}{c}0.7500^{* * *} \\
(0.0298)\end{array}$ \\
\hline year-, region-, industry-FE & yes & yes & yes & yes \\
\hline (year $\mathrm{x}$ region)-FE & yes & yes & yes & yes \\
\hline $\mathrm{R} 2$ & 0.0865 & 0.0889 & 0.0612 & 0.0897 \\
\hline $\mathrm{N}$ & 17,959 & 10,865 & 2,023 & 19,982 \\
\hline
\end{tabular}

Source: German Job Vacancy Survey 2005-2010.

Robust standard errors in brackets. ${ }^{* * *}$ indicates $p<0.01 ;{ }^{* *} p<0.05$; $^{*} p<0.1$. 
Table 9: Difficulty "high wage demands"

\begin{tabular}{|c|c|c|c|c|}
\hline & \multicolumn{4}{|c|}{ OLS } \\
\hline & successful & successful in time & unsuccessful & all vacancies \\
\hline PEA & $\begin{array}{c}0.0306^{* * *} \\
(0.0029)\end{array}$ & $\begin{array}{c}0.0217^{* * *} \\
(0.0031)\end{array}$ & $\begin{array}{c}0.0236 \\
(0.0216)\end{array}$ & $\begin{array}{c}0.0347^{* * *} \\
(0.0031)\end{array}$ \\
\hline low skill & $\begin{array}{c}0.0197 * * * \\
(0.0057)\end{array}$ & $\begin{array}{l}0.0109^{*} \\
(0.0063)\end{array}$ & $\begin{array}{c}0.0419 \\
(0.0395)\end{array}$ & $\begin{array}{c}0.0215^{* * *} \\
(0.0060)\end{array}$ \\
\hline high skill & $\begin{array}{c}0.0069^{* *} \\
(0.0035)\end{array}$ & $\begin{array}{c}0.0031 \\
(0.0035)\end{array}$ & $\begin{array}{c}0.0546^{* *} \\
(0.0259)\end{array}$ & $\begin{array}{c}0.0198^{* * *} \\
(0.0039)\end{array}$ \\
\hline occup. experience required & $\begin{array}{c}0.0111^{* * *} \\
(0.0028)\end{array}$ & $\begin{array}{c}0.0077^{* * *} \\
(0.0029)\end{array}$ & $\begin{array}{c}0.0759^{* * *} \\
(0.0228)\end{array}$ & $\begin{array}{c}0.0222^{* * *} \\
(0.0030)\end{array}$ \\
\hline firm size (ln) & $\begin{array}{c}-0.0026^{* * *} \\
(0.0010)\end{array}$ & $\begin{array}{c}-0.0034^{* * *} \\
(0.0010)\end{array}$ & $\begin{array}{c}0.0168^{* *} \\
(0.0076)\end{array}$ & $\begin{array}{c}-0.0025^{* *} \\
(0.0011)\end{array}$ \\
\hline "financial constraints" & $\begin{array}{c}0.0371^{* * *} \\
(0.0069)\end{array}$ & $\begin{array}{c}0.0302^{* * *} \\
(0.0077)\end{array}$ & $\begin{array}{c}0.1099 * * * \\
(0.0351)\end{array}$ & $\begin{array}{c}0.0483^{* * *} \\
(0.0073)\end{array}$ \\
\hline "low sales" & $\begin{array}{c}0.0220^{* * *} \\
(0.0046)\end{array}$ & $\begin{array}{c}0.0115^{* *} \\
(0.0051)\end{array}$ & $\begin{array}{c}0.0733^{* * *} \\
(0.0254)\end{array}$ & $\begin{array}{c}0.0299^{* * *} * \\
(0.0049)\end{array}$ \\
\hline "not enough suitable empl." & $\begin{array}{c}0.0864^{* * *} \\
(0.0071)\end{array}$ & $\begin{array}{c}0.0805^{* * *} \\
(0.0100)\end{array}$ & $\begin{array}{c}0.0679^{* * *} \\
(0.0234)\end{array}$ & $\begin{array}{c}0.1038^{* * *} \\
(0.0070)\end{array}$ \\
\hline year-, region-, industry-FE & yes & yes & yes & yes \\
\hline (year $\mathrm{x}$ region)-FE & yes & yes & yes & yes \\
\hline $\mathrm{R} 2$ & 0.0457 & 0.0405 & 0.0907 & 0.0558 \\
\hline $\mathrm{N}$ & 27,554 & 16,780 & 2,023 & 29,577 \\
\hline
\end{tabular}

Source: German Job Vacancy Survey 2005-2010

Robust standard errors in brackets. ${ }^{* * *}$ indicates $p<0.01 ;{ }^{* *} p<0.05 ;{ }^{*} p<0.1$. 
Table 10: Difficulty "high wage demands"

\begin{tabular}{|c|c|c|c|c|}
\hline & \multicolumn{4}{|c|}{ Probit } \\
\hline & successful & successful in time & unsuccessful & all vacancies \\
\hline PEA & $\begin{array}{c}0.3057^{* * *} \\
(0.0268)\end{array}$ & $\begin{array}{c}0.3149 * * * \\
(0.0393)\end{array}$ & $\begin{array}{c}0.0726 \\
(0.0656)\end{array}$ & $\begin{array}{c}0.2891^{* * *} \\
(0.0240)\end{array}$ \\
\hline low skill & $\begin{array}{c}0.1637^{* * *} \\
(0.0422)\end{array}$ & $\begin{array}{l}0.1223^{*} \\
(0.0652)\end{array}$ & $\begin{array}{c}0.1310 \\
(0.1185)\end{array}$ & $\begin{array}{c}0.1652^{* * * *} \\
(0.0390)\end{array}$ \\
\hline high skill & $\begin{array}{c}0.0855^{* *} \\
(0.0346)\end{array}$ & $\begin{array}{c}0.0683 \\
(0.0513)\end{array}$ & $\begin{array}{c}0.1653^{* *} \\
(0.0764)\end{array}$ & $\begin{array}{c}0.1720^{* * * *} \\
(0.0295)\end{array}$ \\
\hline occup. experience required & $\begin{array}{c}0.1137 * * * \\
(0.0262)\end{array}$ & $\begin{array}{c}0.1135 * * * \\
(0.0385)\end{array}$ & $\begin{array}{c}0.2382^{* * *} \\
(0.0704)\end{array}$ & $\begin{array}{c}0.1819 * * * \\
(0.0236)\end{array}$ \\
\hline firm size $(\ln )$ & $\begin{array}{c}-0.0240^{* *} \\
(0.0097)\end{array}$ & $\begin{array}{c}-0.0501^{* * *} \\
(0.0143)\end{array}$ & $\begin{array}{c}0.0525^{* *} \\
(0.0227)\end{array}$ & $\begin{array}{c}-0.0197^{* *} \\
(0.0085)\end{array}$ \\
\hline "financial constraints" & $\begin{array}{c}0.2799 * * * \\
(0.0434)\end{array}$ & $\begin{array}{c}0.3079 * * * \\
(0.0640)\end{array}$ & $\begin{array}{c}0.3242^{* * *} \\
(0.0958)\end{array}$ & $\begin{array}{c}0.2937^{* * * *} \\
(0.0383)\end{array}$ \\
\hline "low sales" & $\begin{array}{c}0.1688^{* * *} \\
(0.0333)\end{array}$ & $\begin{array}{c}0.1178^{* *} \\
(0.0515)\end{array}$ & $\begin{array}{c}0.2147 * * * \\
(0.0726)\end{array}$ & $\begin{array}{c}0.1784^{* * * *} \\
(0.0292)\end{array}$ \\
\hline "not enough suitable empl." & $\begin{array}{c}0.5180^{* * *} \\
(0.0350)\end{array}$ & $\begin{array}{c}0.6127 * * * \\
(0.0560)\end{array}$ & $\begin{array}{c}0.2002^{* * *} \\
(0.0690)\end{array}$ & $\begin{array}{c}0.5380^{* * *} \\
(0.0305)\end{array}$ \\
\hline year-, region-, industry-FE & yes & yes & yes & yes \\
\hline (year $\mathrm{x}$ region)-FE & yes & yes & yes & yes \\
\hline $\mathrm{R} 2$ & 0.0921 & 0.1018 & 0.0732 & 0.0955 \\
\hline $\mathrm{N}$ & 27,276 & 15,619 & 2,001 & 29,390 \\
\hline
\end{tabular}

Source: German Job Vacancy Survey 2005-2010.

Robust standard errors in brackets. ${ }^{* * *}$ indicates $p<0.01 ;{ }^{* *} p<0.05$; $^{*} p<0.1$. 


\section{References}

[1] Acemoglu, D. and R. Shimer, (1999), Holdup and Efficiency with Search Frictions, International Economic Review, 47, 651-699.

[2] Addison, J.T. and P. Portugal, (2002), Job serach methods and outcomes, Oxford Economic Papers, $54,505-533$.

[3] Albrecht, J., Pieter A.G., and S. Vroman, (2006), Equilibrium Directed Search with Multiple Applications, Review of Economic Studies, 73, 869-891.

[4] Blau, D.M., and P.K. Robins, (1990), Job search outcomes for the employed and unemployed, Journal of Political Economy, 98 (3), 637-655.

[5] Burdett, K., S. Shi and R. Wright, (2001), Pricing and Matching with Frictions, Journal of Political Economy 109, 1060-1085.

[6] Casella, A., and N. Hanaki, (2008), Information Channels in Labor Markets: One the Resilience of Referral Hiring, Journal of Economic Behabior and Organization 66, 492-513.

[7] Fougère, D., J. Pradel, and M. Roger, (2009), Does the public employment service affect search effort and outcomes?, European Economic Review 53, 846-869.

[8] Galenianos, M., (2013), Learning About Match Quality and the Use of Referrals. Review of Economic Dynamics 16, 668-690.

[9] Galenianos, M., (2014), Hiring through Referrals. Journal of Economic Theory 152, 304-323.

[10] Galenianos, M. and P. Kircher, (2009), Directed Search with Multiple Job Applications, Journal of Economic Theory, 114, 445-471.

[11] Gautier, P., B. Hu, and M. Watanabe, (2015), Marketmaking Middlemen, Tinbergen Institute Working paper.

[12] Gregg, P., and J. Wadsworth, (1996), How effective are state employment agencies? Jobcentre use and job matching in Britain, Oxford Bulletin of Economics and Statistics, 58 (3), 442-467.

[13] Guerrieri, V., R. Shimer and R. Wright, (2010), Adverse Selection in Competitive Search Equilibrium, Econometrica, 78, 1823-1862.

[14] Holzer, H.J., (1988), Search method by use by unemployed youth, Journal of Labor Economics,6, $1-20$.

[15] Launov, A., and K. Wälde (2014), The employment effects of reforming a public employment agency, mimeo.

[16] Masters, A. (2007), Middlemen in Search Equilibrium, International Economic Review, 48, 343362.

[17] Moen, E. R. , (1997), Competitive Search Equilibrium, Journal of Political Economy, 105, 385-411.

[18] Müller, A., M. Rieben, and M. Stops (2011), Einschaltungspotenzial fr den Arbeitgeber-Service der Bundesagentur für Arbeit: Ergebnisse aus der IAB-Erhebung des Gesamtwirtschaftlichen Stellenangebots, IAB-Stellungnahme, 10, 1-15. 
[19] Osberg, L., (1993), Fishing in different pools: Job-search strategies and job finding success in Canada in the Early 1980s, Journal of Labor Economics, 11 (2), 348-386.

[20] Peters, M., (1991), Ex Ante Pricing in Matching Games: Non Steady States, Econometrica, 59, 1425-1454.

[21] Peters, M., (2001), Limits of Exact Equilibria for Capacity Constrained Sellers with Costly Search, Journal of Economic Theory, 95, 139-168.

[22] Pissarides, C., (1979), Job Matching with State Employment Agencies and Random Search, The Economic Journal, 89, 818-833.

[23] Pollard, E., F. Behling, J. Hillage, and S. Seckesser, (2012), Jobcentre Plus Employer Satisfaction and Experience Survey 2012, Research Reort No 806, Department for Work and Pensions, UK.

[24] Rubinstein, A., and A. Wolinsky. (1987), Middlemen, Quarterly Journal of Economics 102, 581593.

[25] Shi, S., Frictional Assignment I: Effciency, Journal of Economic Theory, 98, 232- 260.

[26] Watanabe, M., (2010), A Model of Merchants, Journal of Economic Theory, 145, 1865-1889.

[27] Watanabe, M., (2013), Middlemen: A Directed Search Equilibrium Approach, Tinbergen Institute Working paper.

[28] Weber, A., and H. Mahringer, (2002), Choice and success of job search methods, Empirical Economics, 35, 153-178.

[29] Wielgosz, J.B., and S. Carpenter (1987), The effectiveness of alternative methods of searching for jobs and finding them: An exploratory analysis of the data bearing upon the ways of coping with joblessness, American Journal of Economics and Sociology, 46 (2), 151-164.

[30] Yavas, A., (1994), Middlemen in Bilateral Search Markets, Journal of Labor Economics 12, No. 3, 406-429. 